\title{
Preocupações Epistêmicas na Perspectiva de Segunda-Pessoa para a Responsabilidade Moral
}

[Epistemic Concerns for Moral Responsibility in the Second-Person Perspective]

\section{Beatriz Sorrentino Marques}

Resumo: As condições para a que um agente seja moralmente responsável por sua ação suscitam preocupações epistêmicas, como, por exemplo, se o agente precisa saber o que faz e se ele precisa saber o significado moral do que faz para ser responsável. Veremos que essas preocupações epistêmicas estão presentes em teorias com enfoque na perspectiva de segunda-pessoa. A preocupação com se o agente sabe o que faz é menos controversa, já a preocupação com se ele sabe o significado moral da ação veremos que gera respostas diferentes, de acordo com cada teoria. Além disso, é importante examinar se alguma preocupação epistêmica constitui uma condição independente de outras condições sobre a produção da ação para ser moralmente responsável, ou se as preocupações epistêmicas já são endereçadas pelas condições sobre a produção da ação. A independência é defendida por Mele, com quem concordamos a esse respeito.

Palavras-chave: Segunda-Pessoa. Responsabilidade Moral. Condição Epistêmica.

\begin{abstract}
The conditions under which an agent can be considered morally responsible for her action raise epistemic concerns like, for instance, whether an agent needs to know what she is doing, and if she must know the moral meaning of what she's doing to be held responsible. We'll see that these epistemic concerns appear in theories which focus on the second-person perspective. The concern about the question whether the agent knows what she does is less controversial, but the one about the knowledge of the moral meaning generates different answers according to each theory. Furthermore, it is important to examine either, if some epistemic concern constitutes a condition independent from other conditions for moral responsibility in the production of the action, or if the epistemic concerns are already addressed in the conditions to produce the action. The independency is defended by Mele, and we agree with him on that score. Keywords: Second Person. Moral Responsibility. and Epistemic Condition.
\end{abstract}

${ }^{*}$ Professora Adjunta da Universidade Federal do Mato Grosso (UFMT). Atualmente realiza pesquisa de pós-doutorado em filosofia na Universidade de Brasília (UnB). E-mail: bsorrentinom@gmail.com. http://orcid.org/0000-0001-7192-0777 


\section{Introdução}

Quando se discute as condições para a responsabilidade moral, surgem preocupações epistêmicas, ou seja, preocupações a respeito do que o agente deveria estar ciente $^{1}$ para ser moralmente responsável pela ação. É comum se pensar que o agente precisa estar ciente da ação para ser responsável por ela, o que não é o caso, por exemplo, quando você leva o livro do colega para casa em vez do seu. Trata-se do mesmo livro e o colega deixou seu exemplar na sua mesa, mas você só se dá conta de que não é o seu exemplar quando chega em casa e lê o nome dele na contracapa. Você não se deu conta de que estava levando o livro de outra pessoa. Outra preocupação epistêmica é que o agente precisaria estar ciente da relevância moral da ação, como quando uma pessoa sabe que é reprovável comer o lanche que você deixou na geladeira para sua próxima refeição, mas o faz mesmo assim (e imaginando que você não terá como saber quem surrupiou sua comida). Contudo, não há consenso entre filósofos se estar ciente de que se está fazendo algo moralmente reprovável é de fato necessário para a responsabilização.

Considerando que geralmente se aceita que a condição para a responsabilidade moral envolve condições sobre a produção da ação que resultaria na ação ter sido produzida com o tipo adequado de controle, ou resultaria na ação ser livre, essas preocupações epistêmicas podem ser vistas como uma condição adicional. Outra opção, como defende Mele (2010), é que as preocupações epistêmicas já são endereçadas e satisfeitas dentro da condição da produção da ação (que Mele chama de condição de liberdade) e que, portanto, uma condição epistêmica independente não é necessária. Mele está correto a esse respeito. Veremos algumas teorias, agrupadas sob a classificação de teorias com enfoque na perspectiva de segunda-pessoa, que apresentam em suas formulações não apenas a preocupação epistêmica a respeito do agente estar ciente do que faz, mas também a respeito dele estar ciente do significado moral da ação. 2. Darwall (2010) e Strawson (1962) não tratam a preocupações com o significado moral da ação como uma condição para a responsabilidade moral—embora eles deem importância ao fato de que o agente seja um agente moral. Já Fischer e Ravizza (1998) tratam essa preocupação como um requisito relevante. Contudo, em nenhum dos casos essa é uma condição adicional, independente da condição da produção da ação.

Para discutir essas questões, na primeira seção a perspectiva de segunda-

\footnotetext{
${ }^{1}$ Usarei estar ciente [be aware] ou ter ciência para indicar que o agente tem consciência de algo A, por exemplo, a ação. Não me comprometo com qual seria o veículo dessa consciência, podendo ser uma crença ou conhecimento.

${ }^{2}$ Tomo emprestado o termo de Rudy-Hiller (2018).
} 
pessoa será apresentada. Na segunda seção, será defendido que duas prestigiosas teorias contemporâneas sobre responsabilidade moral dão relevância à perspectiva de segunda-pessoa na responsabilização, as teorias de Strawson e de Fischer e Ravizza. Na terceira seção, serão apresentadas a discussão dobre a independência da condição epistêmica, brevemente o debate a respeito da relevância do significado moral das ações para a responsabilidade moral e como as teorias com enfoque na perspectiva de segunda-pessoa tratam do significado moral das ações. Finalmente, será possível concluir que, embora essas teorias deem importância ao significado moral das ações seja, Darwall e Strawson não chegam a impor que estar ciente desse significado seja uma condição necessária para a responsabilidade moral, mas Darwall indica que o agente precisa ao menos ser competência para estar ciente. Já Fischer e Ravizza, exigem em sua teoria que o agente reconheça um padrão de razões morais, o que sugere que o agente precisa estar ciente de pelo menos algum significado moral da ação.

\section{A perspectiva de segunda-pessoa nas ações}

A condição de segunda-pessoa é a condição na qual um agente se encontra quando interage com outra(s) pessoa(s). Esse tipo de condição ou perspectiva surge dentro de uma comunidade em que as pessoas (agentes) interagem entre si e na qual se aceita que as pessoas têm autoridade para fazer demandas e afirmar direitos nessas interações (uma comunidade moral), por exemplo, de modo geral, é comum que as pessoas afirmem que têm direito a terem sua integridade física preservada ou de não serem enganadas sobre assuntos relevantes para suas vidas. Segundo Darwall (2006, 2010), é a condição de segunda-pessoa-de participante de interações com outros agentes-que garante a autoridade de fazer demandas válidas e endereçá-las a outros agentes. A demanda válida é uma razão de segunda-pessoa ${ }^{3}$ para que o endereçado aja de acordo com essa razão.

Essa proposta de Darwall introduz a noção de condição ou perspectiva de segunda-pessoa, que embasa a autoridade da demanda, e a noção de razão de segunda-pessoa, que é como Darwall batiza a razão normativa em questão. Essa é a condição na qual nos encontramos nas interações com outras pessoas da comunidade, bem como é a condição na qual as outras pessoas estão quando interagem conosco e com outros, e dela derivam as razões normativas que balizam as ações nessas interações. A presente discussão estará focada na condição da segunda-pessoa que assumi-

\footnotetext{
${ }^{3}$ Razões de segunda-pessoa são um tipo de razão moral.
} 
mos no que concerne a ações, especificamente ações intencionais. Para esclarecer tal condição, Darwall explica que se trata de assumir uma perspectiva:

Por "perspectiva de segundapessoa," eu quero dizer a perspectiva que você e eu tomamos quando nós endereçamos reivindicações ou demandas (putativamente válidas) a alguém, seja explicitamente, na fala, ou implicitamente, em pensamento, seja a outros ou a nós mesmos (como em sentimentos de culpa autoendereçados). $4^{4}$ (Darwall, 2010, p. 216)

Numa entrevista, concedida a Dall'Agnol (2006), Darwall explica que a perspectiva de segunda-pessoa é a perspectiva assumida quando as pessoas fazem demandas ou reivindicações válidas a outras pessoas. Fazer demandas pressupõe uma condição [standing] ou autoridade de segunda-pessoa. Além disso, pressupõe que a demanda seja uma razão para agir de acordo com ela (uma razão de segunda-pessoa) e que aquele a quem a demanda é endereçada seja responsável (por agir de acordo) perante quem faz a demanda. Isso sugere que o demandante tem um direito, o que para Darwall, é um conceito que envolve uma condição ou autoridade para fazer demandas a outras pessoas (Dall'Agnol, 2006)..$^{5}$

Uma das questões relevantes tratadas por Darwall é porque as pessoas teriam certos direitos que lhe permitem fazer demandas a respeito de como outros agentes agem ou deixam de agir. Expor as razões pelas quais tais demandas e responsabilização são possíveis é particularmente relevante, porque Darwall afirma que a perspectiva de segundapessoa não apenas permite que agentes sejam responsáveis, mas é a única proposta que oferece razões válidas para que sejam responsáveis..$^{6}$ Por isso, não basta afirmar que as demandas constituem razões para agir, pois se razões em segunda-pessoa dependem da autoridade daquele que faz uma demanda ou que tem uma expectativa de que outros ajam de modo a respeitar seus direitos, essa postura ou condição implica que o demandante tenha a autoridade para tal. Porém, outra implicação importante é que a demanda é endereçada a alguém, ou seja, há uma parte endereçada que deve ser responsável perante o demandante, por isso a razão para agir

\footnotetext{
4"By the "second-person standpoint," I mean the perspective you and I take up whenever we address (putatively valid) claims or demands to someone, whether explicitly, in speech, or implicitly, in thought, whether to others or to ourselves (as in self-addressed feelings of guilt)." (Darwall, 2010, p. 216)

${ }^{5}$ Vale a pena notar também que Darwall admite que assumir a perspectiva de segunda-pessoa e conceder que outras pessoas têm a autoridade que a perspectiva implica, envolve conceder que elas agem livremente, no sentido de não estarem sendo coagidas a agir. A proposta, portanto, não depende da falsidade da tese do determinismo causal (Dall'Agnol, 2006, p. 125).

${ }^{6}$ Não será apresentada uma reconstrução de todo o argumento de Darwall para a justificação, focaremos apenas nos pontos cruciais para a presente discussão.
} 
é chamada de razão de segunda-pessoa.

Para explicar por que nós somos responsáveis uns perante os outros, Darwall diz que é preciso que agentes tenham certa competência para tal:

É suficiente para ser um agente moral nesse sentido que a criatura tenha as capacidades psíquicas necessárias para entrar em relações de responsabilização mútua, isto é, para assumir uma perspectiva de segundapessoa em relação a si mesmo e a outros, e regular sua conduta a partir desse ponto de vista. (Chamemos isso de competência de segunda-pessoa). (Darwall, 2010, p. 221) 7

Assim, o próprio agente se responsabiliza por suas ações, bem como outras pessoas (a comunidade moral) o responsabilizam. Qualquer demanda, ou expectativa, pressupõe que os agentes que interagem compartilham essa competência de segunda-pessoa e, portanto, que eles têm a autoridade requerida para fazer demandas. É possível então ver que a responsabilidade moral é um conceito de segunda-pessoa, pois surge nas interações e exige que os agentes tenham essa competência de segunda-pessoa.

Dito de maneira simplificada, Darwall defende que o caráter de segunda-pessoa da responsabilidade moral mostra que a responsabilização por uma ação é justificável, pois o agente tem competência para tal e atribui a si e a outros a autoridade necessária para fazer demandas. Assim, essa competência permite que o agente seja candidato a atitudes reativas (termo originalmente usado por Strawson). $]^{8} \quad \mathrm{~A}$ demanda ou expectativa de uma pessoa numa interação é justificada, portanto, pelo caráter de segunda-pessoa da responsabilização, bem como pela competência de segunda pessoa dos agentes (inclusive, um indivíduo que sente culpa estaria assumindo uma perspectiva de segunda-pessoa, pois ele se responsabiliza pela ação pela qual se sente culpado). Esse é o caso, pois há uma interação entre os indivíduos competentes envolvidos e a avaliação da ação não é feita por uma terceira pessoa, mas por um indivíduo perante o qual se é responsável.

Retomando então a questão da autoridade, a autoridade deriva do compartilhamento da condição de segundapessoa pelos agentes e é pressuposta nas interações:

\footnotetext{
7 "It is sufficient to be a moral agent in this sense that a being have the psychic capacities necessary to enter into relations of mutual accountability, that is, to take a second-person perspective on himself and others and regulate his conduct from this point of view. (Call this second-personal competence.)" (Darwall, 2010, p. 221)

${ }^{8}$ Atitudes que as pessoas com as quais nos relacionamos podem ter em relação a nós devido a uma ação e que nós podemos ter em relação a essas pessoas. Elas podem variar dentro de um amplo escopo, desde ressentimento até gratidão (Strawson, 1962).
} 
Quando presumimos a autoridade de endereçar uma demanda a alguém e responsabilizar a pessoa pela obediência a ela, temos que supor que a pessoa a quem a demanda foi endereçada, portanto, tem uma razão (uma razão de segundapessoa) que ela mesma pode reconhecer e governar-se de acordo.9 (Darwall, 2010, p. 224)

Razões de segunda-pessoa, então, estão conectadas à responsabilização. Contudo, vale a pena salientar que, segundo Darwall, é possível não estar ciente de uma razão em segunda-pessoa e pela qual o agente seria responsável por agir de acordo. Contudo, Darwall defende que não se pode responsabilizar uma pessoa como participante da interação por uma demanda que sabemos que ela não estava em condições, ou na posição, de reconhecer ou de saber, nem mesmo em princípio (Darwall, 2010 , p. 225). Por essa razão a autoridade de demandar algo de outra pessoa só é possível se for razoável esperar que a pessoa reconheça a demanda, o que implica que ela reconhece a autoridade do demandante e tem condições de reconhecer a demanda.

Assim, de acordo com a descrição de Darwall da perspectiva de segundapessoa é possível perceber que o reconhecimento de demandas das pessoas dentro da comunidade moral é importante para a responsabilização moral. Como participante da interação com as pessoas da comunidade o agente precisa reconhecer a autoridade dessas pessoas e suas demandas, o que significa que o agente reconhece as demandas como sendo morais, dado que a autoridade deriva da participação na comunidade moral. Darwall aceita que se o agente não está na posição e reconhecer a demanda, ele não pode ser responsabilizado, sendo assim, Darwall aceita que o reconhecimento do significado moral tem relevância na responsabilização. Mais será dito sobre isso na seção três, mas antes serão apresentadas outras propostas que dão ênfase às interações em segunda-pessoa.

\section{A responsabilidade moral como participante da interação}

Para além da proposta de Darwall sobre a perspectiva de segunda-pessoa, outras teorias também dão importância ao reconhecimento de razões morais para a responsabilização, bem como do reconhecimento de que o próprio agente pode ser responsabilizado. Ou seja, associam a responsabilidade moral à con-

\footnotetext{
9 "When we presume the authority to address a demand to someone and hold her responsible for compliance, we have to assume that our addressee thereby has a reason (a second-personal reason) that she herself can recognize and govern her- self by" (Darwall, 2010, p. 224).
} 
dição de segunda-pessoa nas interações entre agentes. O tom desse tipo de proposta certamente não é estranho às teorias sobre responsabilidade moral. Assim, embora outras teorias não usem o termo perspectiva de segunda-pessoa, a ideia é capturada pelas suas justificações para a responsabilização.

Strawson em Freedom and Resentment (1962), inova ao concentrar sua discussão sobre a responsabilidade moral nas práticas de atribuição de responsabilidade nas quais agentes se engajam. O seu foco está nas atitudes reativas, as atitudes e reações das pessoas envolvidas em interações com outros agentes, em que é possível que haja partes ofendidas e/ou partes beneficiadas. Assim, Strawson apresenta considerações que podem ser enquadradas no escopo conceitual da condição de segunda-pessoa, o escopo da participação das relações interpessoais. As atitudes reativas desempenham um papel muito importante em nossas vidas sociais, pois nos importamos com as ações que outras pessoas desempenham e que nos afetam. Igualmente, nos importamos se essas ações refletem atitudes consideradas boas ou positivas, como boa vontade e consideração, ou não.

Assim como Darwall, Strawson considera que algumas situações tornam inapropriadas atitudes reativas em re- lação à uma ofensa, por exemplo, a coação. Não é o caso que nunca seja inapropriado ter atitudes reativas em relação ao agente em questão, mas é inapropriado no caso da ofensa feita sob coação, desconhecimento, manipulação, compulsão ou similar. ${ }^{10}$ A base para a responsabilização moral fica clara quando Strawson avalia a inadequação de uma postura objetiva (de terceirapessoa) para argumentar que as práticas e responsabilização moral são eficazes para regular o comportamento social. O problema, segundo Strawson é que a postura objetiva exclui as atitudes reativas, e com elas, elementos cruciais da responsabilização moral. Os conceitos pertinentes para o filósofo, pertencem ao escopo do que Darwall chama de postura de segunda-pessoa, como a participação em interações com outras pessoas que também são candidatas a atitudes reativas.

Atitudes reativas de desaprovação de uma ação, como o ressentimento, surgem quando uma demanda de uma pessoa não é levada em consideração. A atitude-reativa de ressentimento não é uma atitude de exame em terceira pessoa do agente que fez a ofensa, pois isso implicaria separá-lo ou distanciá-lo da comunidade na qual está inserido como agente que interage com outros agentes (Strawson, 1962, p. 23). É justamente

\footnotetext{
${ }^{10}$ Strawson considera que o determinismo só ameaçaria a adequação de atitudes reativas se, caso o determinismo seja o caso, os agentes sejam sempre vistos como estando numa situação em que atitudes reativas são inadequadas, como acontece com a coerção, manipulação, etc. Ele conclui que isso provavelmente não aconteceria. Se o determinismo for o caso, nós dificilmente mudaríamos como vemos nossas relações interpessoais.
} 
por estar inserido nessas interações que o agente é responsável. O distanciamento é próprio da postura objetiva. Ao contrário disso, atitudes reativas derivam justamente de o agente ofensor ser visto como membro da comunidade moral, e é como tal, que ele pode ser responsabilizado.

As interações que envolvem atitudes reativas são aquelas em que fazemos demandas de uma pessoa a outra, de outra pessoa a nós mesmos, e de nós mesmos para outras pessoas, pois os agentes fazem parte da comunidade moral (Strawson 1962). Assim, a justificação para a atitude-reativa (e possivelmente para a punição ou retratação) é a participação nessa comunidade. Strawson sugere que a justificação oferecida pelas atitudes reativas recupera o sentido dos conceitos morais de merecimento, responsabilidade, culpa e punição. 11

Quando a teoria destaca as práticas de responsabilização, ela traz para o foco o que Darwall chama de perspectiva em segunda-pessoa. Assim, é interessante destacar a justificação para a responsabilização, que se baseia na participação do agente de interações com outros agentes, em que ele tem atitudes reativas em relação a esses outros agentes e, por isso, também é um candidato a atitudes reativas.

Fischer e Ravizza também desenvolvem uma proposta que leva em consideração o que Darwall chama de perspectiva de segunda-pessoa, pois além de suporem que os agentes devem se reconhecer como candidatos a atitudes reativas, eles também precisam ser capazes de reconhecer razões morais para agir. De acordo com os autores, sua teoria, o semi-compatibilismo, segue a deixa de Strawson. Eles acreditam que atitudes reativas mostram que temos uma perspectiva particular de pessoas, o que nos leva a nos engajarmos com outras pessoas, diferentemente daquilo que não consideramos como pessoas, como objetos, pois não temos atitudes reativas em relação a essas outras entidades.

Estabelecer as condições para a aplicação do conceito de responsabilidade moral é o objetivo de Fischer e Ravizza, assim, eles visam tornar possível saber em quais circunstâncias um agente seria moralmente responsável. Essas condições não exigem que o determinismo

\footnotetext{
${ }^{11}$ Para Strawson, a responsabilização não requer que abandonemos os fatos e entremos na metafísica.

${ }^{12}$ Resumindo, os casos estilo-Frankfurt seguem o estilo de um caso desenvolvido por Frankfurt (1969) em que o agente não poderia ter agido de outro modo, mas a intuição geral é de que ainda assim ele é moralmente responsável por sua ação. Isso é relevante no contexto porque na literatura sobre livre-arbítrio e responsabilidade moral, aqueles que acreditam que a responsabilidade moral depende da falsidade do determinismo defendem que o determinismo elimina a possibilidade de o agente ter agido de modo diferente de como agiu, ou seja, que ele pudesse ter elegido outra ação, ou simplesmente não ter agido como agiu. A possibilidade de ter agido de outro modo está no cerne de como esses filósofos concebem o livre-arbítrio e as condições para a responsabilidade moral, assim, a possibilidade de atribuir responsabilidade ao agente por sua ação dependeria de se ele podia ter agido de outro modo. Dito isso, o caso proposto por Frankfurt é um contraexemplo a essa ideia, pois o agente não poderia ter agido de outro modo, mas Frankfurt avalia que ele é moralmente responsável por sua ação.
} 
seja falso para que o agente seja moralmente responsável. Os autores aceitam que os casos estilo-Frankfurt ${ }^{12}$ mostram que mesmo que o determinismo seja o caso, isso não interfere na responsabilização dos agentes por suas ações. Há muita discussão em torno dos casos estilo-Frankfurt, mas não a abordaremos. É suficiente para os propósitos da presente discussão deixar claro que Fischer e Ravizza aceitam sua conclusão.

Sendo assim, as condições para a responsabilidade moral que eles visam desvelar não envolvem a condição de que o agente pudesse ter agido de outro modo, o que eles chamam de controle regulador sobre a ação. Em vez disso, Fischer e Ravizza estão interessados em outro tipo de controle, o que eles chamam de controle de direcionamento, que eles comparam ao controle que um agente tem ao guiar um carro. Quando conduzimos e giramos o volante para a esquerda, o carro vai para a esquerda e dizemos que controlamos o carro, independentemente de se pudéssemos ter virado para a direita ou não. Para os filósofos, ter controle de direcionamento de uma ação é o que garante a responsabilidade moral sobre uma ação. Como exemplificam as infrações de trânsito, responsabilizamos condutores por como guiam os carros.

Assim, a tarefa de apontar as condições para a responsabilidade moral passa a ser a tarefa de apresentar as condições para se ter controle de direcionamento de uma ação. As condições apresentadas por Fischer e Ravizza são as seguintes: que o mecanismo (processo) do qual resulta a ação responda a razões e que o mecanismo do qual resulta a ação seja do próprio agente. Essa segunda condição visa evitar casos de manipulação, como nos casos estilo-Frankfurt. Já a primeira condição exige que, quando o mecanismo opere, o agente reconheça razões que existem para agir, especialmente razões morais, e reaja a essas razões agindo por essas razões. Para os filósofos, uma ação é intencional quando é feita por razões, ou seja, não basta agir de acordo com a razão para agir, é preciso agir por essa razão, e só se tem controle de direcionamento de uma ação intencional.

De acordo com o semi-compatibilismo, não basta reconhecer razões para agir uma vez, é preciso que, quando o mecanismo do qual resulta a ação opere, o agente regularmente reconheça um padrão de razões, especialmente razões morais, coerente, inteligível e fundamentado na realidade. Já a condição de

\footnotetext{
O caso envolve um manipulador que pode ser, por exemplo, um neurocientista que instalou um dispositivo no cérebro do agente, e que quer que o agente, Jones, faça A. Quando Jones está prestes a decidir se vai fazer A ou outra coisa, o manipulador observa e, se Jones estiver inclinado a fazer algo que não seja A, o manipulador interfere, de modo que Jones faz A. Fica claro que Jones não poderia ter agido de outro modo. Mas no exemplo de Frankfurt, o manipulador não precisa entrar em ação, pois Jones decide por conta própria fazer A e o faz. Embora Jones não pudesse ter agido de outro modo, dado que o manipulador tomaria providências para que ele fizesse A, nossa intuição é de que Jones é responsável por ter feito A. Esse caso oferece a Frankfurt o ponto de partida para sua conclusão de que é possível não ter possibilidades alternativas de ação abertas ao agente e ele ainda assim ser moralmente responsável pela ação.
} 
reagir a razões é mais fraca, pois casos de akrasia não excluem responsabilização. Portanto, um agente que reconhece adequadamente razões morais, mesmo que acabe falhando em escolher agir de acordo com ela ou em agir por essa razão, é moralmente responsável. Por exemplo, um agente que reconhece que apoiar o filho pequeno indo ao seu recital é razão suficiente para ir ao recital, mas acaba indo para casa descansar por fraqueza de vontade, é moralmente responsável por ter ido para casa. A ideia é que, se quando o mecanismo opera existe um cenário em que o agente teria reagido a razões, então isso é suficiente para mostrar que o mecanismo é reativo a razões.

O mecanismo não é claramente descrito por Fischer e Ravizza. Grosso modo, eles dizem que se trata do processo que resulta na ação, por exemplo, o raciocínio prático. Para que o mecanismo seja do próprio agente, segundo os autores, deve haver um processo por meio do qual o agente assume responsabilidade, em que ele se vê como origem de suas escolhas e ações, i.e., ele se vê como agente e reconhece que suas ações têm efeitos no mundo (Fischer e Ravizza 1998, p. 210). Além disso, o agente reconhece que suas ações podem ser louvadas ou condenadas por aqueles à sua volta. Isso significa que ele tem alguma noção das práticas sociais e de que ele está sujeito a atitudes reati- vas legítimas de outros agentes, dadas essas práticas. Finalmente, é preciso que as crenças do agente de que é um agente e candidato a atitudes reativas sejam baseadas em evidências, como na percepção dos efeitos de suas ações no mundo e nas experiências passadas em que suas ações foram louvadas ou condenadas. É isso o que torna a ação do agente sua ação.

Fischer e Ravizza, por exemplo, supõem que um agente que não aceita responsabilidade por uma ação pela qual é culpabilizado por outros não é retirado de sua comunidade moral. Pelo contrário, a ausência de sentimento de culpa pode ser uma razão a mais para que a comunidade se ressinta com ele. Essa é uma falta adicional. Mas se o agente reiteradamente não reage às atitudes reativas que lhe são direcionadas, é o caso de se pensar que esse agente não faz parte da comunidade moral, pois não assumiu responsabilidade por si mesmo. Fischer e Ravizza concluem que já não nos ressentimos com ele como uma pessoa e "[...] começamos a tratá-lo como um objeto desagradável ou como um animal perigoso (ou irritante) $)^{\prime 13}(1998$, p. 213).

Considerando o exposto, é possível perceber também no semicompatibilismo características do que Darwall chama de perspectiva de segunda-pessoa. Saltam aos olhos alguns aspectos, como a importância de

13 “...] begin treating him as we would a distasteful object or a dangerous (or annoying) animal” (1998, p. 213). 
fazer parte de uma comunidade moral em que o agente atribui responsabilidade aos outros agentes e também é responsabilizado por eles. Mas um desenvolvimento particularmente interessante é o enfoque em assumir responsabilidade, algo que apenas o agente pode fazer, embora não seja feito de maneira solitária. Assumir responsabilidade exige, além de se perceber como agente, entender que faz parte de uma comunidade moral na qual as próprias ações são moralmente avaliadas. Assim, se destacam aspectos compatíveis com o que Darwall chama de perspectiva de segunda-pessoa, especialmente na dependência que a responsabilização tem da participação numa comunidade moral, bem como na dependência que assumir responsabilidade tem do reconhecimento de que se é um candidato a atitudes reativas.

Além disso, é importante ressaltar que a responsabilidade moral depende da interação do agente com outros agentes dentro de uma comunidade que se caracteriza por ser moral. Segundo Fischer e Ravizza, apenas agentes morais, agentes que respondem a demandas morais, podem ser responsabilizados. Para responder a demandas morais, o agente precisa reconhecer razões morais para agir.

Razões morais derivam do equilíbrio entre os interesses do agente em oposição aos interesses e direitos de outros (Fischer e Ravizza 1998, p. 76). Os filósofos dizem ainda que o agente deve reconhecer que as demandas de outras pessoas da comunidade são razões morais, que se aplicam a ele e que, às vezes, os interesses dos outros têm mais peso do que os do próprio agente (1998, p. 77). Como já foi exposto na apresentação da proposta de Darwall, o reconhecimento da demanda de outro que se aplica a si acontece nas interações, quando o agente está na condição de segunda-pessoa, e faz parte da perspectiva de segunda-pessoa reconhecer que algumas razões para agir fazem parte do escopo moral, o que Darwall chamou de razões de segunda-pessoa. $\mathrm{Na}$ próxima seção veremos como a necessidade de reconhecimento de razões morais, uma exigência epistêmica, situa a teoria quanto à preocupação sobre estar ciente do significado moral da ação.

\section{A postura de segunda pessoa en- volve preocupações epistêmicos para a responsabilização}

\subsection{Haveria uma condição epistêmica in- dependente?}

Quando tratamos de condições para a responsabilização moral, surgem questões a respeito do que o agente precisa estar ciente ou saber. Essas são condições epistêmicas e algumas referências ao que o agente está ciente ou reconhece aparecem nas teorias que propõem uma perspectiva de segundapessoa, por exemplo, Strawson expli- 
cita que o agente precisa saber o que está fazendo. Além disso, muito da discussão sobre a perspectiva de segundapessoa envolve razões morais ou razões de segunda-pessoa-demandas e direitos de outras pessoas. Assim, é importante perguntar se é necessário que o agente reconheça essas demandas. Como vimos, Darwall diz que o agente precisa estar na posição de, pelo menos em princípio, reconhecer a demanda para ser responsabilizado. As diferentes posições parecem sugerir que há outra preocupação epistêmica, além de saber o que se faz, a saber, que o agente saiba o significado moral da ação (Rudy-Hiller 2018).

Antes de tratar dessas preocupações, é importante notar que a própria ideia de que haja condições epistêmicas para a responsabilidade moral que sejam independentes das condições para que a ação seja livre é um ponto de discussão. Embora alguns autores separem a condição epistêmica da condição da liberdade (Fischer e Ravizza 1998), Mele (2010) defende que não está claro que a condição epistêmica exija algo que já não esteja englobado pela condição da liberdade.14 Aqui, eu concordo com Mele. Embora eu proponha dar atenção às preocupações epistêmicas das teorias apresentadas, isso não significa que isso constitua um critério epistêmico para a responsabilidade moral independente dos critérios relacionado à produção da ação (que Mele chama de critério de liberdade). Mesmo que preocupações epistêmicas não constituam um critério independente, é importante notar que essas preocupações estão incluídas na condição de produção da ação.

Mele (2010) defende que, apesar de Fischer e Ravizza (1998, p. 13) afirmarem que há condições epistêmicas para a responsabilidade moral que são distintas das condições relevantes para liberdade, esse não é o caso nem mesmo de acordo com a teoria deles. Mele argumenta que, de acordo com a teoria semi-compatibilista de Fischer (2006, p. 21), agir livremente é identificado com exercer controle de direcionamento. ${ }^{15}$ Ainda mais importante, Fischer e Ravizza afirmam que ao exercer controle de direcionamento, o agente age intencionalmente (1998, p. 64), ou seja, por razões. Mele conclui que se exercer controle de direcionamento é agir livremente, então apenas ações intencionais podem ser livres.

A caracterização de ações intencionais é importante para o argumento de Mele. Na ortodoxia da filosofia da ação, ações são caracterizadas como tais por terem pelo menos uma descrição intencional (Davidson, 1963). Podemos individualizar ações, por exemplo,

\footnotetext{
${ }^{14} \mathrm{O}$ enfoque de Mele é a teoria de Fischer e Ravizza (1998), mas é provável que suas conclusões possam se estender para outras teorias.

${ }^{15}$ Mele ressalta, contudo, que não está claro que isso signifique exercer controle de direcionamento da ação em específico, e.g., que fazer A livremente é o mesmo que exercer controle de direcionamento de A especificamente.
} 
com base em diferentes descrições do que o agente fez (Davidson, 1963). Um agente coloca açúcar no café e, inadvertidamente, arruína o café para sua visita (o agente não sabia que sua visita tem horror de café adoçado) e essas são duas descrições distintas do que o agente fez. ${ }^{16}$ No caso, colocar açúcar no café é algo que o agente fez sob uma descrição intencional, já arruinar o café é algo que ele fez sob uma descrição não-intencional.

Assim, retomando a questão sobre as ações livres, o ponto que Mele quer marcar é que o agente livremente adoça o café, sob essa descrição. Mas se a descrição de arruinar o café para sua visita não é intencional, então não é livre. Essa avaliação é independente de uma condição epistêmica a respeito do que o agente sabia ou deveria saber para ser moralmente responsável. Mele defende que basta a condição de liberdade da teoria de Fischer e Ravizza para mostrar que o agente não é moralmente responsável por arruinar o café para sua visita, pois ele o faz não-intencionalmente e não o faz livremente, assim, não preenche o requisito do semi-compatibilismo para a responsabilização moral. Portanto, embora os autores declarem que as condições epistêmicas são distintas da condição da liberdade, Mele conclui que nenhuma condição epistêmica é necessária para a responsabilização além da condição de liberdade, pelo menos de acordo com os elementos apresentados pelo semi-compatibilismo de Fischer e Ravizza.

Mele salienta, contudo, que o semicompatibilismo também requer que, quando o mecanismo do qual resulta a ação opere, o agente reconheça razões morais. Essa condição para a responsabilidade moral é uma condição epistêmica. Porém, é importante notar que também não é distinta da condição de liberdade, pois esse é um dos requisitos para o controle de direcionamento. Discutirei a seguir que as teorias que propõem uma perspectiva de segunda-pessoa, não apenas o semicompatibilismo, adicionam preocupações epistêmicas à discussão sobre a responsabilização moral. Não obstante, isso não significa dizer que essas preocupações resultem em condições epistêmicas que sejam independentes da condição de liberdade.

Saber se o agente tem ciência do que faz é uma condição para a responsabilização está no cerne da discussão sobre condições epistêmicas para a responsabilidade moral (Rudy-Hiller 2018). Contudo, Mele defende que essa dimensão epistêmica já faz parte dos pressupostos para que uma ação seja intencional, assim, no que concerne às condições para a responsabilidade moral, ele argumenta que atribuímos res-

\footnotetext{
${ }^{16}$ Uma proposta alternativa é individualizar as ações de modo que se tratam de duas ações e a primeira causa a segunda (Goldman, 1971). Não tomo uma posição a respeito de qual das duas propostas de individualização de ações está correta, e Mele parece acreditar que ambas são compatíveis com seu argumento. Para simplificar usarei os elementos teóricos de Davidson.
} 
ponsabilidade moral por ações intencionais. Porém, essa não é a única preocupação epistêmica relacionada à responsabilidade moral, pois há um debate também a respeito da necessidade do agente ter ciência do significado moral da ação.

\subsection{Significado moral}

Outra condição apresentada como condição epistêmica para a responsabilidade moral diz que o agente precisa estar ciente do significado moral de sua ação para ser moralmente responsável (Rudy-Hiller 2018). Contudo, não há consenso formado sobre a questão e há filósofos que discordam que essa seja uma condição necessária para a responsabilidade. Zimmerman (2018) defende que a condição é necessária e que não estar ciente de que a ação é errada, por exemplo, eximiria o agente de responsabilidade. Meu enfoque será mostrar que as teorias que consideram uma perspectiva de segunda-pessoa, como as de Darwall, Strawson, Fischer e Ravizza, dão relevância ao agente reconhecer o significado moral de sua ação. Resta saber se esses filósofos acreditam que não se dar conta desse significado exime o agente de responsabilidade. $\mathrm{Ou}$ seja, se essas teorias defendem que estar ciente do significado moral da ação é condição para a responsabilidade moral e se essa é uma condição epistêmica independente da condição da liberdade. Mas primeiro é preciso entender a dis- cussão a respeito do significado moral das ações.

Dito de forma simplificada, Zimmerman (2018) defende que a ignorância de que se está agindo errado em muitos casos elimina a possibilidade de responsabilização. Assim, ele defende que é uma condição epistêmica para a responsabilização que o agente esteja ciente do significado moral da ação. Ignorância deve ser entendida como a falha em acreditar que está agindo errado quando essa proposição é verdadeira. A ignorância é ilibatória quando o agente age a partir da ignorância, ou seja, o agente não teria feito o que fez se acreditasse que era errado fazê-lo. A culpabilidade viria de agir errado estando ciente de estar agindo errado.

Zimmerman exemplifica a aplicação de sua proposta com um caso em que alguém que está cuidando de uma criança lhe dá leite para beber, mesmo depois dos pais da criança terem lhe dito que ela tem alergia a leite. Porém, o cuidador esqueceu do aviso, portanto, quando deu leite para a criança acreditava que estava dando leite para ela, mas não acreditava que estava dando para a criança algo do qual ela tem alergia, nem que estava fazendo algo errado. Portanto, o cuidador não poderia ser responsabilizado.

Acredito que muitos discordariam dessa conclusão. Harman (2011) argumenta que não é a mera ignorância que exclui a responsabilização, mas que o agente tenha agido com base numa 
crença falsa. Assim, não basta que um agente não tenha em mente a norma que está violando para que não seja responsabilizado com base na sua ignorância (momentânea) da norma. Além disso, ao contrário de Zimmerman, há filósofos que defendem que o agente não precisa estar ciente de que sua ação é moralmente reprovável para ser responsabilizado, basta que o agente esteja ciente de aspectos da ação que a tornam moralmente reprováveis, por exemplo, que a ação fará mal para outra pessoa. Talbert (2013) defende uma ideia desse tipo.

Para preparar o terreno para o argumento, Talbert chama a atenção, por exemplo, para os julgamentos valorativos de um agente que não percebe-ou negligência-o significado moral de sua ação, pois tendemos a notar as coisas que valorizamos. A falha em perceber, por exemplo, que uma pessoa está sendo desrespeitada por sua ação, pode indicar que o agente não julga os interesses ou a dignidade dessa pessoa como sendo importantes, embora Talbert também admita que esse não seja sempre o caso. Há situações em que as pessoas não se dão conta de algo importante por causa do estresse ou cansaço.

Outra possibilidade que Talbert explora é que aquilo que o agente ignora, o significado moral da ação, é um ponto de desacordo entre as partes. Por exemplo, $\mathrm{S}$ decide fazer $\mathrm{A}$ e embora $\mathrm{A}$ vá prejudicar um colega, $C, S$ não vê a ação A como moralmente errada, en- quanto que $\mathrm{C}$ a vê como tal. Talbert aceita que essa distinção entre avaliações evidencia uma distinção de valores. Quando os valores por trás de uma ação são menos distantes para as partes, há uma tendência a compreender por que o agente agiu de maneira moralmente condenável, esse é o caso porque não lhe parecia condenável, e se compartilhamos valores similares, mesmo que julguemos a ação como moralmente condenável, nos aproximamos de vê-la como desculpável.

Assim, a culpabilidade, segundo Talbert, repousa sobre um desacordo moral entre as partes. Mas o filósofo defende que são as razões que temos para culpabilizar o agente que importam, não se o agente reconhecia essas razões. Ora, se a ação de um agente é uma manifestação de sua racionalidade prática e controle, então Talbert aceita que é apropriado ter atitudes reativas em relação ao agente, mesmo que ele não reconheça as razões morais pelas quais é culpabilizado. No fim das contas, a ação foi intencional e desdenhosa com relação aos interesses da parte prejudicada, por exemplo, ao fazer A, S desdenha dos interesses de C. Se for possível concordar que os interesses e bem-estar de C são valiosos, então parece que o desdém de $\mathrm{S}$ ao fazer A é moralmente reprovável. Nesse sentido, o que vale é a razão da vítima, e dos que têm empatia por ela, para responsabilizar o agente, pois o bem-estar da vítima é uma razão para agir, quer o agente a 
tenha reconhecido ou não.

Por isso, Talbert argumenta que, para que as atitudes e julgamentos de um agente mostrem que sua ação é culpável, é mais relevante que ele esteja ciente das consequências da ação para a vítima do que do significado moral de sua ação. Se $S$ sabe que vai prejudicar $\mathrm{C}$, então parece ser possível atribuir a $\mathrm{S}$ o julgamento de que o prejuízo a $\mathrm{C}$ não era relevante o suficiente para que não fizesse A. Sendo assim, $C$ está justificado em objetar ao tratamento que $S$ lhe dispensou e demandar que seus interesses sejam considerados.

Zimmerman e Talbert exemplificam a disputa entre aqueles que defendem que é necessário para a responsabilização moral que o agente esteja ciente do significado moral de sua ação e aqueles que defendem que não é necessário, respectivamente. Resta saber como as teorias que adotam a perspectiva de segunda pessoa se encaixam nessa discussão, pois vimos que elas dão relevância considerável ao agente reconhecer as demandas de outros agentes como demandas morais.

\subsection{O significado moral em perspectivas} de segunda-pessoa

Vimos que a perspectiva de segundapessoa tem lugar quando o agente participa de uma comunidade moral, em que as pessoas atribuem autoridade umas às outras para fazer demandas, que são razões para agir. A participação numa comunidade moral é condição para a responsabilização. Se esse é o caso, está pressuposto que os agentes da comunidade sejam capazes de reconhecer essas razões de segunda-pessoa como tal, como demandas válidas de pessoas que têm autoridade para fazer demandas, que também podemos chamar de razões de segunda-pessoa, que são um tipo de razão moral. Assim, teorias que endossam a perspectiva de segunda-pessoa pressupõem que o agente reconhece razões morais para agir como sendo morais, ou seja, que o agente está ciente do significado moral de sua ação. Uma questão importante então é saber se essa é uma condição necessária para a responsabilização nessas teorias.

Para Darwall, demandas de outras pessoas são razões de segunda-pessoa para agir. Essas razões dependem conceitualmente da autoridade para fazer demandas implícita ou explicitamente (Darwall 2010, p. 216). Os direitos de outros que têm autoridade para fazer demandas (mesmo não explícitas) são razões de segunda-pessoa, mas e se um agente não se dá conta da demanda, ou seja, ou do significado moral de sua ação? A esse respeito, é importante notar que Darwall considera ininteligível responsabilizar alguém como participante, ou seja, numa perspectiva de segunda-pessoa, com base em uma demanda que essa pessoa não estava na posição de reconhecer, nem mesmo em princípio (2010, p. 225). Isso significa que se a pessoa não poderia ter re- 
conhecido, nem mesmo em princípio, a demanda que é a razão de segundapessoa, então ela não pode ser responsabilizada por não atender à demanda em questão.

Se esse é o caso, ela não precisa reconhecer a demanda específica em questão, mas precisa ser possível, em princípio, que ela reconhecesse. Por exemplo, um agente que considera apenas brincadeira fazer bullying com um colega, chamando-o por nomes xenofóbicos, não se dá conta da demanda do colega de não ser discriminado, mas poderia ter se dado conta, pois sabe o que é bullying e conhece o teor xenofóbico dos termos usados.

Se essa interpretação estiver correta, então Darwall não exige que o agente esteja ciente do significado moral de sua ação para que seja responsabilizado por ela, pois o agente poderia falhar em reconhecer uma demanda e ainda assim ser moralmente responsável, desde que em princípio ele pudesse reconhecêla. Isso leva a crer que o agente precisa ter a capacidade para reconhecer de razões de segunda-pessoa, como a própria teoria afirma, ele precisa ser um participante da comunidade moral e ter competência de segunda-pessoa, mesmo que não reconheça toda a razões moral que lhe toca. Assim, a preocupação a respeito do significado moral da ação não constitui uma condição epistêmica necessária, mas uma caracterização de qual tipo de entidade pode ser um agente moral. A exigên- cia da participação numa comunidade moral e que o agente possa, ao menos em princípio, reconhecer razões de segunda-pessoa, implicam que ser um agente moral envolve algumas capacidades epistêmicas, como ser capaz de reconhecer demandas morais. Contudo, como isso faz parte da caracterização do agente como tendo uma perspectiva de segunda-pessoa, tampouco constitui uma condição epistêmica independente.

Talvez algo semelhante seja o caso de Strawson. Ele faz menção apenas à necessidade de o agente saber o que está fazendo (1962, p. 7), mas considerando que as atitudes reativas refletem as demandas que fazemos de outros, que outros fazem de outros e que fazem de nós, é possível presumir que Strawson aceite que as pessoas precisariam ser capazes de reconhecer essas demandas como demandas morais. Afinal, essas são demandas de manifestações de boa vontade e consideração, segundo o filósofo (1962, p. 16), portanto, atender a essas demandas envolve reconhecer o significado moral do que está sendo demandado. Mas Strawson não dá sinais de que seja uma condição necessária para a responsabilização de uma ação específica, ele apenas defende que esse é o tipo de interação que mantemos quando exercemos nossas práticas de responsabilização. Se o agente interage com outros agentes e reconhece que é um candidato a atitudes reativas tanto quanto outros agentes, isso seria 
suficiente para responsabilizar o agente por sua ação. Embora Strawson dê uma indicação de que o agente ignorar o mal que fazia possa ser tratado como atenuante da responsabilidade (1962, p. 8), acredito que uma interpretação mais simples seja supor que se exclui a responsabilização em casos em que o agente não se deu conta das consequências (negativas) de sua ação para a outra pessoa, mas ele não precisaria estar ciente do significado moral de sua ação.

Já Fischer e Ravizza, defendem que a responsabilidade moral requer que, quando o mecanismo que resulta na ação opere, o agente regularmente reconheça (um padrão de) razões morais que há-reconheça as demandas dos outros. Ao adicionar essa condição de reconhecimento de razões morais, Fischer e Ravizza esperam que os agentes tomem as demandas dos outros como demandas morais, não como razões prudenciais, por exemplo, que pode ser melhor para si não desagradar certa pessoa. Eles esperam que, quando o mecanismo do qual resulta a ação opere, o agente reconheça um padrão de razões morais que se aplicam a ele. Assim, o agente precisa tomar razões morais como sendo morais, o que implica reconhecer o significado moral de sua ação. Isso não significa apenas que sua ação está de acordo ou não com as demandas de outras pessoas, mas que o agente entende essas demandas como demandas morais e que seriam razões para agir de outro modo.
Diferente do que Darwall defende, Fischer e Ravizza incluem o reconhecimento de razões morais dentre as condições para o controle de direcionamento que o agente precisa ter para ser moralmente responsável. Lembremos, contudo, que Fischer e Ravizza defendem que é preciso reconhecer um $p a-$ drão de razões, dentre elas, razões morais suficientes para ter agido de outro modo, o que não significa dizer que é preciso reconhecer todas as razões morais que existem (Fischer e Ravizza 1998, p. 77). Mas dado que é preciso reconhecer pelo menos algumas razões morais, é difícil dizer que o agente não estaria minimamente ciência do significado moral de sua ação. Digamos que um jovem, Paulo, acredita que o colega estrangeiro, Jorge, trapaceou em um jogo e resolve confrontar Jorge imediatamente. Jorge reage de maneira zombeteira e, estando na frente de outras pessoas, Paulo acredita que a situação faz com que ele pareça tolo perante os presentes. Paulo avalia que tem razão suficiente para responder com xingamentos xenofóbicos. Paulo reconhece que um pedido de desculpas de Jorge, que a presença da mãe de Jorge no ambiente, ou a presença de outros colegas estrangeiros seriam razões, cada uma suficiente, para agir de outro modo. As duas últimas são razões morais, Paulo está ciente de que seria ofensivo a essas pessoas fazer xingamentos xenofóbicos em sua presença. Portanto, embora Paulo não tenha considerado que 
Jorge tem o direito de não ser ofendido ou tratado de maneira preconceituosa, não parece que ele não estivesse ciente do significado moral de sua ação, i.e., que seria ofensiva.

Talvez o agente não tenha ciência de todas as demandas que lhe tocam, mas Fischer e Ravizza consideram que o agente precisa ter ciência de parte delas. Provavelmente em casos em que se reconhece apenas uma ou quase nunca se reconhece alguma razão moral, pensaríamos que esse não é um agente moralmente desenvolvido, mas um agente que reconhece alguma razão moral se dá conta, ao menos parcialmente, do significado moral de sua ação. Assim, é possível concluir que, para a proposta de Fischer e Ravizza, estar ciente do significado moral das ações é importante para a responsabilidade moral, pois é necessário reconhecer alguma razão moral (como moral) suficiente para ter agido de outro modo e reconhecer a força dessa razão, por exemplo, que os interesses de outro podem pesar mais do que o próprio em algumas situações. Contudo, essa não é uma condição epistêmica independente das condições de produção da ação que Fischer e Ravizza consideram relevantes para a responsabilidade moral, ou seja, as condições para que o agente tenha controle de direcionamento.

\section{Considerações finais}

Vimos que preocupações a respeito do que o agente precisa saber para ser moralmente responsável por sua ação permeia as discussões sobre responsabilidade moral. Teorias que não fazem menção a condições epistêmicas e mesmo as que afirmam não tratarem de condições epistêmicas (Fischer e Ravizza 1998) envolvem preocupações epistêmicas em suas propostas. As teorias focadas na perspectiva de segundapessoa não são diferentes, aliás, elas dão importância ao agente estar ciente não apenas da sua ação, mas do significado moral da ação dentro da comunidade moral. $\mathrm{O}$ agente precisa reconhecer a demanda válida de outra pessoa como uma razão de segunda-pessoa para agir. Sendo assim, o agente agiria ou não de acordo com essa demanda estando ciente de seu significado moral.

Como vimos, Darwall e Strawson não propõem que o agente precise estar ciente do significado moral da ação específica que faz para ser moralmente responsável por essa ação, mas Darwall deixa claro que o agente precisa ter competência de segunda-pessoa. Por outro lado, Fischer e Ravizza sugerem que o agente precisa reconhecer alguma razão moral que seria razão suficiente para agir de outro modo, o que leva a crer que o agente precisa ter alguma ideia do significado moral de sua ação. Finalmente, é importante ressaltar que essas preocupações epistêmicas 
estão contidas na condição de produção da ação (condição de liberdade) e não constituem nessas teorias uma condição epistêmica independente. As teo- rias, nem mesmo a de Fischer e Ravizza, não apresentam razões para crer que haja uma condição epistêmica independente, portanto, concordo com Mele.

\section{Referências}

DALL'AGNOL, D. "Morality from the second-person standpoint". ethic@ - An international Journal for Moral Philosophy, 2006, v. 5, n. 2, p. 121-125.

DARWALL, S. The second-person standpoint: morality, respect, and accountability. Cambridge: Harvard University Press, 2006.

DARWALL, S. "Precis: the second-person standpoint". Philosophy and Phenomenological Research, 2010, v. 81, n. 1, p. 216-228.

DAVIDSON, D. “Actions, reasons, and causes”. The Journal of Philosophy, 1963, v. 60, n. 23, p. 685-700, 1963.

FRANKFURT, H. G. "Alternate possibilities and moral responsibility”. The Journal of Philosophy, 1969, v. 66, n. 23, p. 829-839.

GOLDMAN, A. I. "The individuation of action". The Journal of Philosophy, 1971, v. 68, n. 21, p. 761-774.

HARMAN, E. “Does moral ignorance exculpate?” Ratio, 2011, v. 24, n. 4, p. 443-468.

FISCHER, J. M. My way: essays on moral responsibility. Oxford: New York: Oxford University Press, 2006.

FISCHER, J. M.; RAVIZZA, M. Responsibility and control: a theory of moral responsibility. Cambridge: Cambridge University Press, 1998.

MELE, A. "Moral responsibility for actions: Epistemic and freedom conditions". Philosophical Explorations, 2010, v. 13, n. 2, p. 101-111.

RUDY-HILLER, F. “The epistemic condition for moral responsibility”. In: ZALTA, E. (Org.) Stanford Encyclopedia of Philosophy, 2018. Disponível em: https://plato.stanford.edu/archives/fall2018/entries/moral-responsibilityepistemic/. Acesso em: 9 fev. 2021.

STRAWSON, P. "Freedom and resentment". Proceedings of the British Academy, 1962, v. 48, p. 1-25.

TALBERT, M. "Unwitting wrongdoers and the role of moral disagreement in blame”. In: SHOEMAKER, D. (Org.) Oxford Studies in Agency and Responsibility Volume 1. Oxford: Oxford University Press, 2013. p. 225-245.

ZIMMERMAN, M. J. "Peels on ignorance as a moral excuse". International Journal of Philosophical Studies, 2021, v. 26, n. 4, p. 624-632.

Recebido: $02 / 02 / 2021$

Aprovado: $12 / 03 / 2021$

Publicado: 30/04/2021 